\title{
XIV. On a native arseniate of lead. Communicated by Charles Hatchet, Esq., F.R.S.
}

\section{Reverend William Gregor}

To cite this article: Reverend William Gregor (1810) XIV. On a native arseniate of lead. Communicated by Charles Hatchet, Esq., F.R.S. , Philosophical Magazine Series 1, 35:142, 87-94, DOI: $10.1080 / 14786441008563030$

To link to this article: http://dx.doi.org/10.1080/14786441008563030

曲 Published online: 18 May 2009.

Submit your article to this journal $\lceil\pi$

Џll Article views: 3

Q View related articles $\square$ 
pil becomes larger, the circle of dissipation increases, and consequently remote objects appear less distinct than they did in the early part of life.

V1.-From this investigation it manifestly appears, that the eye is in reality no more than a machine of a fixed and determinate form, without any power to alter its outward dimensions, or to move any of its internal humours; and that the only arljustment necessary to form a distinct picture of an object upon the retina (whether the object be near or remote) is to prevent diverging rays from entering the eye, and to admit such only as are nearly parallel.

This office is performed by the iris, which contracts the pupil to exclude the side rays when we view near objects, and enlarges this aperture to give us a distinct view of such remote objects as are but faintly illuminated: it is also well known, that whenever the eye is exposed to a strong light, :he pupil contracts, but it expands as the light decreases.

These contractions and dilatations of the pupil, according to the distances of objects and strength of light in which they are seen, are directed by that volition of the mind which presides over and regulates all the other motions of the eye.

Lynn, January 3,18 io.

Ez. WALKer.

XIV. On a native Arseniate of Lead. By the Reverend William Gregor Communicated by Charles HatCHET, Esq., F.R.S.*

I.

$T_{\text {har the oxide of lead and the arsenic acid might be }}$ found in the state of natural combination, is a supposition highly probable, from the strong affinity which subsists between these two substances. But the existence of such a compound has not, as I conceive, hitherto been established by such proofs, as entitle it to be ranked amongst the decided cases of mineralogical science. I trust, therefore, that the observations, which I bave the honour of submitting to the Socie $y$, on a new $\uparrow$ ore of lead lately discovered

* From Philosophical Transactions for 1809, Part 11.

+ It is new at least to the miners in Cornwall; nor was there, previously to this discovery, any ore resembling it to be found in that splendid collection of minerals, which my valuable friend Phili\}, Rashleigh, esq., has :o liberally formed, and as liberally employed in the promotion of science. 
in the county of Cornwall, so justly celebrated as well for the variety as for the richness of its mineral productions, will not be deemed superfluous.

This mineral was raised in the mine called Huel-Unity, a very rich copper mine, in the parish of Gwcnnap. According to the information with which I have been favoured by Mr. William Davy, a very intelligent and experienced miner in that district, it was found in a lode south of HuelUnity principal lode, at the depth of fifty fathoms below the surface, which lode underlay about two fiet in the fathom south: at the depth above mentioned, this lode fell in or formed a junction with another small lorle or vein to the south, and when the junction took place this lead ore was found. The veins of it are, in general, from six to ten inches wide, and they diverge on going west. Some particles of this lead ore have been found in the southern part, after the separation of the lodes; but the northern lode does nut coutain any unt the junction takes place. This ore is intermixed with some native copper, very rich gray copper, and black copper ore, and some is mixed with quartz. The walls of both veins are killas.

\section{Description.}

This mineral is regularly crystallized. The form of its most perfect crystals is an hexahedral prism; they are of different sizes, from one-tenth of an inch in diameter to the size of a hair. The longest which I have seen do not exceed three-tenths of an inch in length : these terminate in a plane, at right angles, with the axis of the prism; but the crystals of a smaller size are frequently drawn out into a very taper acumination, which appears to be a six-sided pyramid. A number of smaller crystals are often closely packed together in bundles, which are bent in different directions, and terminate in a point. The larger crystals either stand alone, or adhere, on their lateral planes, to the gangue, or are confusedly matted togetber in a mass.

Some of them are bollow, as if an internal nucleus had been destroyed; and sometimes this internal nucleus overtops the external lamina. The gangue is a white quartz, which frequently exhibits on its surface the appearance of a partial decomposition.

The red octahedral copper ore, and the copper into which that ore passes, are often intermingled with the crystals of this lead ore and imbedded in them.

The coloum of these crystals consists of a variety of tints of yellow. Some are of a beautitul wine yellow resembling 
the Brazilian topaz: this, in the greater number of specimens, passes into a delicate Isabella-colour: whilst, in uther cases, we have the honey-yellow mingled with brown hues of different intensities: so that we neet with crystals resembling dark brown sugar-candy, or comuon resin.

Some of the crystals are beatitilly transparent, whilst others possess this quality in part only, at their extremities, or in inferior degrees throughout thuir whole lengths.

The external lustre, in some specimens, is vitreous; in others, resinous: but in some instances their surface is partially covered by tender and delicate filaments of a silky lustre. These filaments are sometimes found in a separate state looscly adhering to quartz; and ihey form a variety of this fossil.

The crystals vary as to hardness. The angular fragments of the most transparent are sufficiently hard to scratch glass.

This mineral is easily reduced to powder, which has the appearance of pounded resin; it contracts a yellower tint by long exposure to the air.

The specific gravity of the purest crystals, taken at the temperature of $50^{\circ}$ Fahrenheit, was $6 \cdot 41$.

\section{III.}

A fragment of crystal, exposed to the flame of the blowpipe in a goid spoon, melted into a brownish-yellow mass, which on cooling did not assume any angular figure. it remained in a state of ignition apparently unaltered; but when a piece of it was exposed to the flame on charcoal, a rapid decomposition took place, arsenical vapours were extricated, and globules of a metal, possessing the common properties of lead, were leit behind.

This mineral, in a state of tine powder, is soluble in nitric acid, even without the aid of heat. Care, however, must be taken, that it does not concrete into lumps. The vessel therefore which contains it nust be frequently shaken, and the nitrate of lead produced aust be, from tume to time, dissolved in water, and poured of from the residumn. The process of solution is, honever, accelerned by a digesting beat. Some silica remains, which, as the quantity of it is variable according to checunstinces, appears not to be an essential ingredicnt of this fussil.

The nitric solution is colourless; its transparency is not disturbed by nitrate of barytes. Nitrate of silver renders it turbid, and a small quantity of white curdly matter is deposited. Sulphuric acid and the liquid sulphates produce copious 
copious precipitates of a white heavy matter. If the fluid be poured off from this subsided matter, and it be freed from the superfluous sulphuric acid, by the means of nitrate of barytes, it will yield, on the affusion of liquid nitrate of lead, an abundant white precipitate, which, urged by the flame of the blow-pipe on a support of charcoal, resolves itself into reduced lead and arsenical vapours.

These preliminary experiments led me to the probable conclusion, that this fossil chiefly consisted of oxide of lead, arsenic acid, and a small quantity of the muriatic acid.

\section{Analysis.}

\section{A.}

1. Fifty grains, carefully selected from crystals of a pale Isabella-colour, were reduced to a fine powder, and exposed to a low red heat for about an hour. Their weight was diminished by 0.15 of a grain.

2. The yellowish powder was now transferred to a vessel of pure silver, and mixed with a lixivium containing fifty grains of potash, prepared by the means of alcohol ; a quantity, which $I$ had previously ascertained to be sufficient to effect a complete decomposition of this mineral. The ley was gradually evaporated to dryness in a sand-bath. The soluble part was extracted by distilled water, and poured off from a yellowish white matter, which was sufficiently edulcorated $(a)$.

3. Liquid nitrate of ammonia was now dropped into the alkaline fluid, as long as it produced any cloudiness: the clear fluid was now decanted from a small quantity of white matter, which had subsided, and rendered acid by nitric acid; ammonia, added to excess, produced a slight turbidness. These precipitates, after sufficient edulcoration, were added to the yellowish white residuum $(a)$.

4. The liquid was now rendered slightly acid by nitric acid, and a solution of nitrate * of lead in distilled water was dropped into it, as long as it separated any precipitate. The clear fluid was poured off, and evaporated nearly to dryness, and a small quantity of white matter, thus obtained, was added to the former precipitate, which dried,

* If the colourless liquid oxy -nitrate of lead be dropped into a dilute solution of arsenic acid, or of arseniate of potash acidulated by nitric acid, no immediate precipitation of an arseniate of lead is produced; but crystaline grains are, after a time, gradualy deposited at the bottom of the vessel. But liquid nitrate of lead causes an immediate and abundant precipitate from these same dilute solutions. These two combinations therefore must be different. 
and exposed to a low red heat, weighed, whilst still warm, 10.8, which, according to the proportion of $33: 100$, established by Mr. Chenevix, implies 13.46 of arsenic acid.

p. 5. The superfluous lead was now separated from the fluid by sulphate of soda, and filtered ofl. Ammonia precipitated a minute portion of flaky matter; it weighed, after ignition, 0.2 of a grain; it consisted of silica and oxide of lead, and must be attributed to the nitrate of lead employed.

B.

1. The yellowish white residuum ( $(1)(\mathrm{A}, \S \mathcal{Q}$.) was dissolved without effervescence in nitric acid, except a minute portion of silica, which, after ignition, $=0: 8$. A white heavy matter was thrown down from this solution, by liquid sulphate of soda. The clear decanted fluid was evaporated to a small volume, and sulphate of soda produced a further separation of white matter; it was sulphate of lead, which, after exposure to a low red heat, and weighed, whilst warm, $=47.5$, which, upon the supposition that one hundred parts of sulphate of lead contain $69 \cdot 74$ of lead +3.48 of oxygen, is equivalent to 34.77 of oxide of leacl.

2. The fluid, now freed from lead, deposited, on the affusion of ammonia, a greenish matter, which, after ignition, became red, and $=0.033$ of a grain. It was oxide of iron.

C.

1. One hundred grains of larger crystals, some of which were hollow, and the surfaces of which were slightly and partially covered with silky filaments, treated in the same way yielded 95.983 of sulphate of lead, equivalent to 69.76 of oxide, and 80 of arseniate of lead, which indicates $26^{\circ} 40$ of arsenic acid. The oxide of iron, in this case, amounted to only 05 of a grain, and the residuary silica was in too small a quantity to be weighed.

2. I have endeavoured to decompose this fossil by boiling it to dryness in a solution of four times its weight of the purest subcarbonate of potasin, and exposing the dry mass, fur a very short time, to a low red heat; but I found, that only a part of the arsenic acid had united to the alkali; the larger portion of it was detected in the nitric solution of the residuum; but the relative proportions of the oxide and the acid, were found to correspond almost exactly with the foregoing statement of them.

3. I found also, that carbonate of ammonia precipitated this mineral, in an unaltered state, from its solution in 
nitric acid: as no arsenic acid had united with the precipitant. The solution of the nitrate of ammonia was evaporated to dryness, and exposed to a red heat in a platina crucible; but nothing was left, except a slight trace of oxide of lead. We may infer from hence, the absence of both the fixed alkalies.

4. I found in one specimen only of this fossil any notable difference in the relative proportions of the oxide of lead and of the acid to which it is united. It consisted of crystals confusedly matted together in a more compact mass than this fossil generally assumes. One hundred grains were dissolved in nitric acid; the marine acid was separated by nitrate of silver, and any redundant silver by muriate of ammonia. The lead was separated by sulphuric acid, and the superfluous portion of that acid by nitrate of barytes, and the arsenic acid was combined with the oxide of lead by the affusion of nitrate of lead. The muriate of silver $=9.8$; the sulphate of lead $=97 \cdot 6$, and the arseniate of lead $=72$, equivalent to 1.63 of muriatic acid, $7 \mathrm{~J} .46$ of oxide of lead, and 23.88 of arsennic acid, respectively. The quartz $=0.35$, and the oxide of iron $0^{*} 2$, nearly.

Another portion taken from the same specimen, treated with an alkali, gave very nearly a similar result.

\section{D.}

It will now be necessary for me to speak concerning an ingredient of this fossil, which I may have seemed to overlook. I mean the muriatic acid: I have found some difficulty in ascertaining the proportion which it bears to the other constituent parts, and from a cause which I did not suspect. I considered that the only sure mode of determining this point, was to have recourse to nitrate of silver, which might effect a direct separation of the marine acid from the nitric solution of this fossil. But I found, in many experiments upon given quantities of this mineral, that the results, which I derived from this most valuable chemical test, were variable and uncertain.

At last, I was enabled to trace the error and uncertainty up to two sources. In the first place, I found that the muriate of silver was more abundant in the cases where I employed a vessel with a long neck for the solution, and did not expose it to heat.

I concluded, therefore, that when the process was conducted under different circumstances, the predominating 
mass of nitric acid produced its effect, and volatilized a portion of the muriatic.

Another source of error I found in the following anomalous circumstance, viz. a simultaneous precipitation of a portion of arseniate of lead takes place with that of the muriate of silver. Whatever combination this may be, it is a weak one, and may be severed by nitric acid, which dissolves the arseniate and leaves the muriate ; or by ammonia, which takes up the muriate, to the exclusion of the arseniate.

The conclusion to which many experiments have led me is this, that the muriate of silver produced in the nitric solution of one hundred grains of arseniate of lead by nitrate of silver, amounts to about $9 \cdot 5$.

\section{E.}

In order to prove that the acid, which is combined with the oxide of lead in this mineral, is the arsenic acid, and that it is not combined with phosphoric, I decomposed some of its acid, which had been combined with lead in the foregoing experiments, by means of sulphuric acid, and filtered off the sulphate of lead. The fluid which passed through the filter was evaporated nearly to dryness, and it assumed the appearance of crystalline grains. Some of it was exposed to the flame of the blow-pipe in a gold spoon; at first it became like a white dry powder, which melted before an increased heat: placed on charcoal and ignited, it was totally dissipated in arsenical fumes.

Some of it was dissolved in nater, and, dropped into liquid sulphate of titanium, a white precipitate was produced: combined with soda, it precipitaled silver from the nitrate of silver, of a brick colour. It precipirated mercury from its nitrate, of a yellowish colour, which afterwards became reddish. This precipitate, exposed to the flanse of the blow-pipe on charcoal, exhibited the same phænomena as arseniate of mercury.

I precipitated magnesia from its muriate, and redissolved it by carbonate of ammonia, perfectly saturated with carbonic acid. I divided this liquid into two portions, and dropped into both a solution of the combination of the acid of this mineral and soda. No precipitate was produced. I dropped into oue of the vessels some liquid phosphate of soda, and a separation of saline matter was instantly produced. I soon, however, found, that this mode of distinguishing the phosphoric from the arsenic acid could not te depended upon. For in the other vessel, in which no phosphate of soda had been dropped, in a short time, saline 
tufts made their appearance, and an abundant deposition of saline matter was formed. I found also, that if the solution had been more concentrated, the precipitation would have immediately taken place.

On making a comparative experiment with arsenic acid, I found that it forms a triple salt with ammonia and magnesia, analogous to the phosphoric salt described by Dr. Wollaston. 'The figure of the arsenical salt, as far as I could determine it from a confused crystallization, is a trihedral prism.

We are therefore, I think, authorized from the experiments herein detailed, to conclude, that the fossil which is the subject of this paper is an arseniate of lead, and that, if we state that the relative proportion of the constituent parts of it is in one hundred, as follows, we shall not be far from the truth:

$$
\begin{array}{llr}
\text { Oxide of lead } & - & 69.76 \\
\text { Arsenic acid } & - & 26.40 \\
\text { Muriatic acid } & - & 1.58
\end{array}
$$

The silica and the oxide of iron, which account for a portion of the loss, and the alumina and copper which are gometimes found in an analysis of this fossil, I do not conceive to be essential to it.

The existence of a minute portion of muriatic acid as $\mathbf{a}$ constant ingredient of it, is a curions fact : and it is still more curious, when we consider it in connexion with the analogy that, in this particular, it maintains with the naturak phosphates of lead.

XV. Description of a reflective Goniometer. By WiLliam Hyde Wollaston, M.D., Sec. R.S.*

$F_{\text {Rom the advances that have been made of late years in }}$ crystallography, a very large proportion of mineral substances may now be recognized, if we can ascertain the angular dimensions of their external forms, or the relative position of those surfaces that are exposed by fracture. But though the modifications of tetrahedrons, of cubes, and of those other regular solids, to which the adventitious aid of geometry could be correctly applied, have been determined with the utmost precision, yet it has been often a subject of regret, that our instruments for measuring the angles of crystals are not possessed of equal accuracy, and that in applying the goniometer to small crystals, where the radius

* From Philosophical Traneactions for 1809, Part II. 